\title{
Seasonal Community and Resident's Experience of Place: Case Study of an Evolving Retirement Migration Destination
}

\author{
Yuefang $\mathrm{Wu}^{1, *}$ \\ ${ }^{1}$ Foshan Polytechnic, Foshan, Guangdong 528137, China \\ *Corresponding author. Email: 2556083143@qq.com

\begin{abstract}
Retirement migration as a typical type of mobility characterizes the large scale population movement in China. Interviews conducted with seasonal retirement migrants, local residents and other social parts in Sanya reveal that traditional concept of home is challenged with increased mobility, and social distinction marks the difference between retirement second home and traditional home. A heuristic framework on domains of meaning of home in old age by Oswald \& Wahl (2005) is employed in this research. As an important social strategy to cope with change, acquaintance society formed by "laoxiang" is welcomed by retirement migrants to retain sense of familiarity and one's social status. And it initiates new thoughts on change of Chinese culture.
\end{abstract}

Keywords: Seasonal community, Retirement migration, Home, Laoxiang.

\section{INTRODUCTION}

In today's world, people are increasingly mobile and well-traveled, and images from all over the world are brought directly into their lives; this opens their minds to the possibility of living and buying property anywhere outside of their permanent residency. Globalization, as well as mobilization domestically, promotes new forms of hypermobility, in which the distinction between home and second home, or between sedentarism and nomadism, is blurred (Aledo, 2008). Today's society is marked by growing and increasingly diversified human mobility and migration, and by the emergence of new transitional way of life (Castles and Miller, 1993).

The phenomenon of retirement migration is not isolated but closely connected with various social processes. One obvious link is to tourism: the term 'residential tourists' is sometimes used to describe retired (and other) people who have settled permanently or semi-permanently in the same areas

*Funds: This research is funded by the Funding of Philosophy and Social Science Planning of Guangdong, China (No. GD19YGL01), the United Funding of Fundamental and Applicant Research of Guangdong, China (No.2019A1515110940), and Important Platform and Scientific Project in Guangdong (No. 2018GWQNCX006) as those visited by large numbers of tourists, and whose retirement to these resort areas often follows a personal history of holiday-making in the same destination region (King, Warnes, Warnes, Williams, 2000). International retirement migration is fixed in a continuum between tourism and migration. Retirement migrants are different from short term tourists, in that they establish themselves temporarily or permanently in the host country by buying or renting a residence there. Furthermore, retirement migrants differ in many ways from labour migrants, since leisure, lifestyle and pursue of an ambitious life after retirement (rather than production) are key factors in their migration and stay (Benson \& O'Reilly, 2009; King, Warnes, Warnes, Williams, 2000). They may thus be viewed as consumption-oriented migrants, being on a continuum between permanent migration and tourism (Williams \& Hall, 2000). There are few academic studies of senior tourism or residential tourism, although the need for such research is recognized (WTO, 1997). The mobility of elderly people is a response to pre-retirement stimuli and therefore their current behavior contains strong lines of continuity.

In the context of China, increasing mobility in space and time has added to the complexity of 
Chinese people challenge the way of traditional beliefs and the way of living. For centuries, Chinese seniors do not want to leave home and those who had to leave home for various reasons would find their ways to return home when they are old. Being forced to leave one's hometown and fallen leaves returning to the roots, describing going back home when getting old are two important expressions to understand the Chinese emotional feeling about being away and back home. However, this is very much challenged in the emerging trend of retirement migrants.

Understanding of home and community, and territorial "roots" and social network are destabilized by this development. Thus, the aim of this paper is threefold. In the first place, we probe into the perception of retired migrants regarding home, community and place in the constantly evolving destination. Secondly, we seek to understand how the seasonal migrants perceive difference between home and 'home outside of home' in mobility and experience change in personal encountering with increased housing mobility in aged. Last but not the least, concerns are laid on constructing a research framework to analyze individual's experience of place in an evolving community, and contribute to international research in retirement migration with experience from China.

\section{THE MULTIPLE DIMENSION OF HOME}

There are many descriptions related to home, such as house, household, haven, hometown, paradise, etc. In the discussion of these home related concepts, it can be seen that home has been a topic of academic interest for decades in multiple disciplines. But the key question of "what constitute a home" is still controversial (Lawrence, 1987). Multiple disciplines including environmental, psychology gerontology, and human geography have suggested that the meaning of home among older adults is related to aspects of physical, social and personal bonding, on behavioral, cognitive and emotional levels. For example, Judith Sixsmith (1986) identified three modes of everyday home experience concerning home-related statements: the physical home, the social home, and the perceptional home. The concept of inside-ness is re-applied in Rowles's (1983) research, which is considered central to understand what home means for older people. It covers three elements, such as physical insideness, social insideness and autobiographical insideness.

Overall, there are three dimensions that home is very much related. In its physical form, home is important in providing shelters and protection for domestic activities and concealment, and acting as an entity separating private from public domains (Flade, 1993; Lawrence, 1987). The second dimension is about the social interaction and the activities. Home is a place where familiar people are interacting with each other and which is occupied by the family members and other familiar people. In summary, house is where life takes place and home is about how to live (Ginsberg 1999). Giddens (1984) defined home as "co-existence, inseparable and interaction between space and social unit". It is a physical place where the institutions of social relationships are setup and evolve, and it is a combination of the physical place for residential house and the social-economic unit of household.

The third dimension is its symbolic and emotional meaning. Yet, home also 'involves spatial and physical aspects as well as symbolic and emotional attachments to real or imagined places and people' (Uriely, 2010, p. 855). The conceptual difference between home and house highlights the phycological and sentimental feature of home, for example, in building "a central emotional and sometimes physical reference point in a person's life" (Sixsmith, 1986). As described by Hayward (1975), home is a broad construct capturing ideas about physical structure, territory, locus in space, self and self-identity, and as a social and cultural unit. Thus, it is crucial in individual's identity building and emotional expression. On the other hand, home is regarded as a bridge between objective sociophysical setting and subjective evaluations, emotions and values (Oswald \& Wahl, 2005); and connects past and future for individuals (Cutchin, 2001; Dovey, 1985). It is described as a "spatially localized, temporally defined... physical frame and conceptual system for the ordering, transformation and interpretation of the physical and abstract aspects of domestic daily life" (Benjamin, 1995). The meaning of home on the general level links the person with its environment, and is endowed with special spatio-temporal, sociocultural and spatial meanings that changes with past, present and future activities (Dovey, 1985; Fisher \& Harvey, 2009). Notions of safety, rootedness, joy, privacy, togetherness and recognition are closely connected with the meaning of home throughout lifespan (Zingmark, Norberg 
and Sandman ,1995). In particular, home is very much related to the place where one was born and grew up. It has the meaning of the origin place and a memory and feeling of stability. When the adults leave home, home is often regarded to the hometown to the place where they often visited with their families. It is a place where they want to return to after they have experienced the outside world. The search for home can be lifelong experience for most of people (Tucker, 1994).

\section{HOME IN CHINESE CULTURE}

Although home is universal concept, home has some special features in the Chinese culture. For Chinese people, home is beyond house (concrete building) and social values (family life, privacy and oasis). Historically, people are raised and taught generation after generation to be loyal to the ancestral land and dutiful to their familial lineage - for nourishment, security, enrichment of the family, as well as the source of identity. The worship of ancestors and local gods in China shows the binding of a people to a certain locale. Of special interest here is the "deep undramatic tie to locality" of ancient Chinese, as is illustrated in the Tao Te Ching:

Let us have a small country with few inhabitants... Let the people return to the use of knotted cords [for keeping records]. Let their food be sweet, their clothing beautiful, their homes comfortable, their rustic tasks pleasurable. The neighbouring state might be so near at hand that one could hear the cocks crowing and dogs barking in it. But people would grow old and die without ever having been there (ibid., p.160).

The above reflects the yearning not just for a place, but a past - a past of simplicity and purity, which never have existed, but an ideological construct of a different kind in the mind: an ideological construct of home and contentment against the present-day materialist world of limitless human desires. Until very recently, China was in the agricultural society and people tended not to move. Home land associated with root is highly valued in Chinese culture, which is reflected in the old saying that people hate to leave a place where one has lived long. And the dead is often sent back to his or her hometown for burial. Old people are particularly reluctant to move, they understand that their presence in the old houses also helps to sustain the meaning of home for the children who may be scattered in different places after they grow up. Parents with the old houses bear and preserve the most sincere and precious memory of the big family, providing the safe and stable shelter for them.

Chinese people are more willing to be settled down within their familiar environment or place of birth. As the old saying goes, "When parents are still alive, the sons should not go afar". Home in the Chinese context is often associated with rootedness or place of origin (Su, 2012) and the relationships with the big families.

In the early years of People's Republic of China, centrally planned economy was adopted by the government. People were strictly controlled by the census registration system, which was called "hukou". Residents were labeled rural and urban origin in hukou system, where they were stamped by the status. Mobility was not encouraged in this context, and people are closely tied to the agricultural land or workplace. The census system has profoundly influenced people's perception towards home and family. For example, in the urban area, houses were previously provided by "Danwei" (work unit). Traditional family patterns organized by clanship and consanguinity were replaced by collective dwellings within factory compounds. Individuals are unable to decide on where they live under the central allocation mechanism. Employees of one work unit lived together as a big family and support each other. Workmates sometimes act as the primary member of a family for caring and sentimental outlets. The importance of work unit system is emphasized in the preservation of traditional neighbourhoods and existing social networks (Jankowiak, 1993). However, towards the end of 1990s, welfare housing allocated by the state as a fundamental housing allocation mechanism was abolished, to be replaced by commodity housing provided by the market. Capital became dominant factors in housing distribution. Traditional "danwei housing" and enclosed community dwelling by employers in a specific enterprise is substituted by gated community, which is composed of residents with different occupation and social background. The disintegration of previous neighborhood assembled by friends and workmates has led to the dissolution in resident's sense of community and home. In Ikels' (1996, p.270) study of Guangzhou, she describes a city in moral chaos in which crime and corruption are rampant. 'People fear for their safety after dark and shun public spaces where they could be vulnerable. Old moral codes and conventions are breaking down in the face of rampant marketization and population growth'. It is also reflected by Chan 
(1993) in her study of mutuality in Guangzhou where she observes that urban growth, family breakdown and higher residential mobility threaten 'the kinds of social cohesion that encourages the development of strong reciprocal bonds'. The loss of acquaintance's neighborhood or as stated by Fei (1945) the 'earthbound China' is accompanied by the elimination of tradition, order and etiquette. The elderly are gradually detached from the previous society ordered by geography attachment, workplace relation, consanguinity or clanship, and absorbed by the new community and neighborhood formed by modern society. The elderly also turn into active participant in home making as a process of social bonding and cultural recognition in place away from familiar dwelling. The traditional concept of home, developed through the process of localized everyday practice, and secured by familiarity and sense of certainty, is transformed in a highly mobile world and modernization vortex.

\section{HOME IN MOBILITY}

As we have seen, the notion of home is customarily associated with stability, comfort and familarity, while migrancy is often equated with "homelessness" — a state of uprootedness and changing circumstances - leading to misery and cognitive dissonance. Therefore, the concept of home should be a useful analytical construct with which to study migration, which is, after all, fundamentally concerned with leaving home, moving between homes, or the search for home (Chan, 2003). The literature on home and mobility has widely examined how home becomes a contested space for identity building and capital accumulation, in the case of immigrants (Blunt, 2005a; Blunt \& Varley 2004; Walsh 2011), diaspora and refugees (Blunt 2005b; Valentine et al., 2009). However, tourists have long been neglected in the literature on home and mobility, although they constitute a massive mobile population within and across national borders. Tourism studies predominantly assume that home is a fixed place of residence; that there is a home and away (White \& White, 2007). However, due to high mobility, relations between home and mobility are often blurred and being away from home alone cannot describe the tourism experience. The struggles to call a place home in an increasingly mobile world are thus not confined to conventional diasporic groups, but invoke "a loosely coherent, adaptive constellation of responses to dwelling-indisplacement" (Clifford, 1997).
Tourism-induced seasonal retirement migration is widespread. For older people, home in later life is especially important. With the cease of other social activities in work, older adults are more concerned about their personal well-being and health. Residential mobility process through different time in lifespan may involve several patterns and sequences. For some elderly adults, second homes may be constructed in places of childhood memory and bear rich assembly of "home" or familiar places to return to. While for others, retirement residency may come upon unexpectedly in a journey, where individual will choose to establish a new space of home without past social connection and maintain a place of privacy. Whilst a simplistic perception of a retirement, move it is 'final', to be succeeded only by a forced move into some kind of sheltered accommodation, migrants moving to another place in their late fifties or early sixties can expect another twenty years or so of active life, but also for their circumstances to change, sometimes in ways that encourage further residential moves (King et al., 2000). On the other hand, loss of competence in the old live also hints on subtle change in sense of home and relationship with environment. Overall, the mobility of the olds has not received due attention.

\section{CONCEPTUAL FRAMEWORK OF HOME FOR ELDER PEOPLE}

Oswald and Wahl (2005) developed a synthesis to understand the meaning of home in old age based on theories from environmental psychology and gerontology. The heuristic framework of "meaning of home in old age" comprised of three domains, including physical, social and personal ones, and the personal category is further delineated into cognitive, behavioral and emotional connections to home and community ("Figure 1"). The framework provides a context to understand individual's sense of home through evolution in the life span, and in the meantime bridges the understanding from the micro-scale space surrounding the self, the mesoscale of the interior home environment, and the macro-level of the region (Fisher \& Harvey, 2009). In the meantime, it points to the three fundamental aspects of home experience, and possesses efficiency for measurement and categorization. Thus, it is utilized in this paper as an interpretative framework to probe into the experience of home of the seasonal retirement migrants in China. 

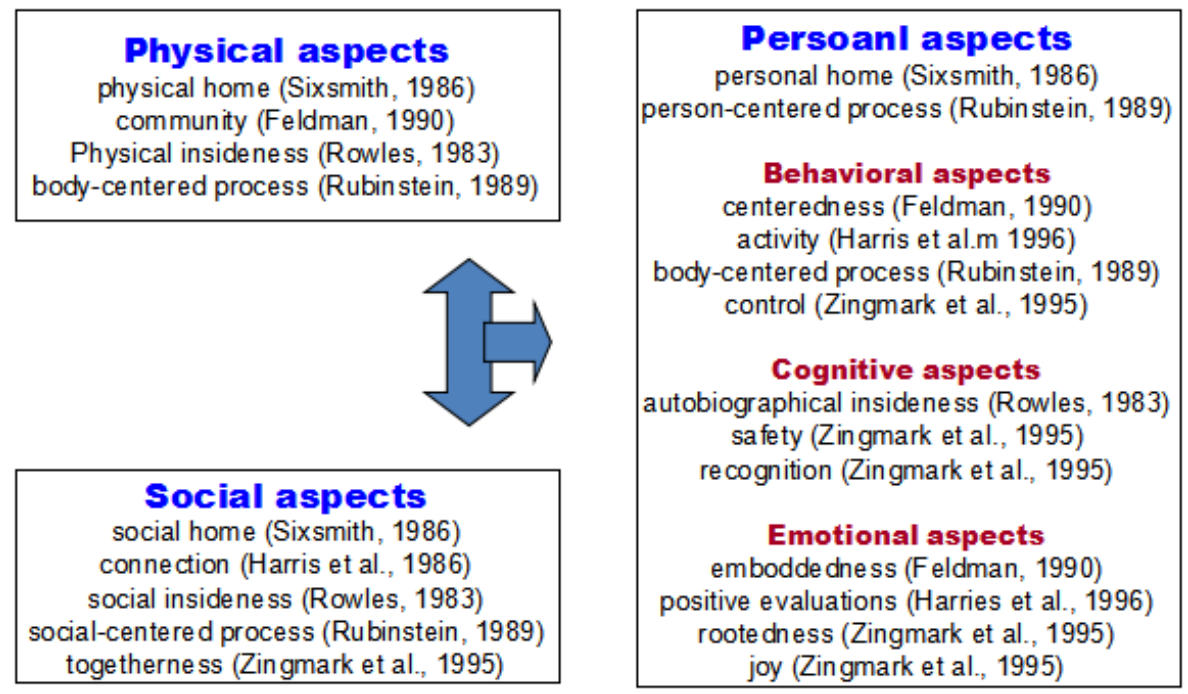

Figure 1 Heuristic framework on domains of meaning of home in old age (Oswald \& Wahl, 2005).

\section{RESEARCH APPROACH}

A qualitative research is conducted to understand the personal experience of home of seasonal retirement migrants to Sanya on Hainan Island in South China. Sanya is a celebrated city for 'Sea, Sand and Sun' vacation and second home lifestyle in China. It is gaining fame for International Tourism Island appointed by the Central Government in 2010, with preferential policies in tourism, land development, finance and sport gambling sectors. The spectacular development of housing property in the past five years has attracted interest from both domestic and international academy. It vividly exemplifies current process of mobility and globalized dwelling, while on the other hand provides an ideal case for retirement migration study in China. Since the focus is on perception, meanings and experience, the research is closely related with its physical, social and spacial-temporal context. As a qualitative research, emphasis is placed on subjective facts and understanding, rather than statistical validity.

Fieldwork researches were conducted in Sanya in 2009, 2010 and 2013. It is the high season when snowbirds from North China get assembled, and Sanya was also under drastic change with national policy stimuli in time. A pilot research was conducted in July, 2009 to ascertain the quantity of second home and the potential for research; major data was collected in 2010, then a re-visit was also carried out by the researchers in January, 2013 to follow-up with the current development locally. The study areas focused on the urbanized areas of
Sanya city, in particular the oceanside constructed areas which were predominantly occupied by snowbirds. Interviews were conducted both in the open area and within communities/villages of participants. A total of 46 interviewees were selected including 28 seasonal retirement migrants, 10 local residents, 4 governmental officials and 4 participants from collage and agency. The retirement migrants aged 60 s to 80 s, spaning from younger retirees in relatively good health to elderly retirees encountering increased physical incompetence.

The interview guide for the seasonal retirement migrants addressed a range of topics including: personal demography, housing type and tenure situation in Sanya and originating areas, motivation for moving, mobility pattern, neighborhood characteristics, daily activity and social bonding, dwelling experience and life encountering in Sanya, perception towards permanent home and second home. Interviews with local residents focus on the social bonding and perception towards new seasonal migrants and their experience of change in their own home space. Interviews with governmental officials and other participants were conducted to obtain contextual facts of policy and social development and to further examine the relationship between seasonal migrants and locals. The Oswald and Wahl framework provided the organizational structure for the analysis in the three domains: physical, social and personal. In physical aspect of home, issues such as natural landscape, housing amenity, neighborhood quality and accessibility to outdoor are considered. Under social aspect of home, things including social 
bonding, interpersonal connection and social insideness are probed into. In personal domains, behavioral (ie., everyday activity, proactive environmental manipulation), cognitive (ie., safety, identity, perceived autonomy, familiarity, routine) and emotional (pleasure and hatred, rootedness, unhomeliness, evaluations) aspects are considered. Themes were extracted, scrutinized and recategorized according to the framework, and further interpretation of the qualitative materials was carried out to build the interrelationships between them.

\section{CASE SITE OF SANYA: RESIDENTIAL TOURISM AND SEASONAL COMMUNITY}

Sanya is characterized by its physical landscape of boundless seashore as well as natural fauna and flora resources. On the other hand, it gets famed for the "Oriental Hawaii" as the one and only tropical city in China. In record from 1971 to 2000, the yearly average temperature reaches $25.8{ }^{\circ} \mathrm{C}$, and lowest temperature appears in January as $18.5^{\circ} \mathrm{C}^{1}$, making it the unique city to enjoy sea diving and surfing all-year-round domestically. With the maturity of tourism industry to grow from sightseeing tourism to holiday-making tourism, Sanya is re-marketed into a desirable destination for residential tourism. In year 2011, overnight visitor reached 10.2 million, and over 0.2 million among them were snowbirds to spend the winter, outgrowing the 0.19 million urban population of Sanya (Statistics of Sanya). In the accommodation sector, there were 223 hotels providing 65,221 beds in 2011. But the majority of residential tourists got their residency through housing department. For instance, in the Spring Holiday of 2011, $70.79 \%$ of the tourists in Sanya were accommodated by guesthouses, rented apartments or self-owned houses, while the others were catered by hotels ${ }^{2}$. Residential real estate investment reached 1.6 billion RMB, accounting to $89.9 \%$ of total real estate investment in 2011, offering $868,500 \mathrm{~m}^{2}$ living space to the market. In particular, 1.66 millions $\mathrm{m}^{2}$ villas and luxury apartments were completed to target external high-end market. Residential property is rapidly growing to be matched in strength with traditional commercial hotels. The above figures are also in close relation with the distinctive property transaction mode of

1. http://zh.wikipedia.org/wiki/\%E4\%B8\%89\%E4\%BA $\% 9 \mathrm{~A} \% \mathrm{E} 5 \% \mathrm{~B} 8 \% 82,8.20$

2. http://finance.ifeng.com/roll/20100223/1846031.html
Sanya. According to statistics, over $90 \%$ of the new built properties are purchased by mainland Chinese, while another $3 \%$ are owned by international buyers (PBS, 2007). The houses are seasonally used or saved for speculation. Thus, the housing vacancy rate sky-rocks every summer, leaving the beachside back to serenity.

\section{HOME ENROUTE: RECONSTRUCTING MEANING OF HOME IN OLD AGE}

\subsection{Person-Environment Reciprocity in Building Physical Home}

The majority of seasonal retirement migrants are motivated to Sanya because of warm climate in winter for cold-avoidance and desirable dwelling environment for health-keeping. The physical attraction of amenity and landscape are most frequently mentioned by the interviewees. Pulling effect by friends and relatives who have already resided there is of primary importance for decision to move. Still, some of the new migrants appear to discover Sanya on their traveling, and after comparison with other destinations in China, they decide to move. One respondent expressed her experience this way, "I stay here for every winter with my husband in the past 4 years. We come in mid-October and leave in March next year. The fantastic landscape as a coastal city attracted us on the first sight. We feel comfortable with the fresh air and warm climate here. We have introduced many workmates and friends in Harbin (in Northeast China) to come, and they think it is good for the joint and trachea diseases (Respondent 2, female)".

For some persons, Sanya typified the slow-pace and tranquility of township, which is in contrast with the "hustle and bustle" of urban life. It reminds the elderly of the past and evokes a sense of nostalgia. Respondent 3 spoke about push factor such as the severe cold winter of her hometown in northeast China, and pull factors related to her childhood memories of keeping a private garden in front of the house and do the farm work to suffice the family, "I like my house in the interior part of the city. It is distant from the tourist and closer to my girlhood memory. I can enjoy the beautiful wetland near our house and do the gardening myself."

Additionally, experience of physical home for seasonal migrants diverges with different dwelling 
history. Retirement migrants staying less time in Sanya generally regard it as a unique and desirable place, and physically different from their usual living environment. They regard it as a sunny place to start another journey in the old age and build up new life circle. However, for those who have established second residency for a long time, they gradually discover the negative side and unsatisfactory changes in Sanya. As mentioned by one interviewee who brought a land lot in the urban village and constructed his own house, the 7 years of seasonal living render deteriorating memory for him. When he said "Sanya is growing into a big city, you can see the crowding of 'snowbirds' and new estate compound along the seaside... We still remember 7 years ago, it was a quiet and remote fishing village. But now things change. The quality of life is not improving for the elderly in-migrants, nor for the locals. The government is not doing anything. We are really disappointed by the current situation (Respondent 4, male)."

When asked about vacationer's attachment to home and community, it became apparent that the perception of many residents was more homecentered than community-center. Their attachment to physical home and close living environment was important for many interviewees despite different living experience. "We regard our house and close relatives in Sanya as home, but the general community is not included (Respondent 4)." And some residents are more inclined to live in their enclosed castle, rather than socializing around in the open space. As stated by a villa owner in the most high-end compound of Sanya, "I come and stay here for about 2 weeks every year, but my families will stay longer. The principle of our life is 'not in my backyard', we don't want to be bothered. We may meet other property owners around the swimming pool and clubhouse. I seldom go to the city center, nor do I have any connection with the locals.(Respondent 5)" However, with the maturity of residential tourism, the tenure type of retirement migrant gets increasingly divergent, which critically influences interpersonal relation building and sense of community. Residential pattern ranges from private home, rented house on a long lease in community, seasonally rented apartment in urban village, to nursing house. Since the latter two housing types are generally found in urban village in or in the peripheral areas of city, the gatekeeping system is looser and sometimes in vacuum. The living space of retirement migrant and local resident is thus mingling, and makes the everyday meeting and crossing unavoidable. The physical alteration of housing environment to some certain extent impacts on the sense of community. "Community means knowing there are people close by that will connect with you some time. When I walk out, I will first go across the living room of house renter. He is a local man, and used to work in the village administration department. Gradually I get interested in their life, and I pay attention to the house furnish, for example the altar they keep to worship sea god and ancestor. And we chat. We are getting closer now. (Respondent 6, female, ages 70 s, first-year vacationer in Sanya)"

The above quote speaks to the complex nature of person-environment relation. The physical setting of dwelling environment is a fundamental factor patterning one's perception of the social and personal home. While the amenity of the area of Sanya initiated a strong pull on many retirement migrants, interviewees revealed some mixed feelings about whether the social ties should be laid down and nurtured here. Social boundary arising from status, language and lifestyle, which surpasses geographical connection, makes the migrant's attachment to local society intricate and vulnerable. As stressed by geographers, "place as process", which acknowledges the dynamism and connected nature of temporal and spatial axes relative to meaning of home and attachment to place and community (Golant, 2003; Wiles, 2005 ${ }^{3}$ ). It is meaningful to integrate the physical-spatial and social-personal dimensions with a developmental mindset in viewing the elderly's sense of home over time.

\subsection{Bonding Acquaintance Circle to Forster Social Home}

Although ideas about "community" are much debated and contested from an academic perspective, individuals seem to have a fairly accordant understanding of what community represents for them. From Fisher and Harvey's (2009) research, community is most often viewed as a geographically demarcated space or place but was also equally likely to emphasize a social dimension capturing notions of connection, socialinsideness and togetherness as conveyed in their

3. Gloant, S.M. (2003) Conceptualizing time and behavior in environmental gerontology: a pair of old issues deserving new thought. The Gerontologist, 43(5), 638-648. Wiles, J. (2005) Conceptualizing place in the care of older people: the contributions of geographical gerontology. Journal of Clinical Nursing, 14(8B), 100-108. 
interview. However, a different scenario seems to appear in Sanya.

Respondent 7, who started winter holidaying in Sanya 3 years ago, suggested that they are still adjusting their position when dealing with locals. He was uncomfortable with local's way of conduct, especially in business doing. He took an example of shopping in the food market. "The vendors speak in local dialect, and I can hardly understand what they are talking about. They have different prices for locals and outsiders, and they look at me up and down before telling the price. What makes me furious is that, they never give me the right weigh! These people are trying to cheat from time to time." Thus, he thought that, he would just maintain a functional relation with the locals, and keep a distance from them. Respondent 8, who has stayed in Sanya for several winter, also stated that, "the locals are tricky and cunning. If you don't keep an eye on them, you will get cheated easily". The migrants were conscious of the difference between themselves and the locals, and rather than making effort to integrate into local society, they were striving to maintain a fortress city protecting their own plots. "There is no communication between the snowbirds and the locals. The locals are of poor hygiene and lazy. It is unlikely for me to mingle with them". (Respondent 10) Concerning the poor living condition of the locals, one respondent also said that, "they deserve it. They are so lazy. Everybody is gambling and no one likes to work. I don't think any part of my imagined home place will include that kind of person." (Respondent 11)

Apart from socializing with the locals, individual's conception towards social aspect of home is also reflected in the interrelation between retirement migrants of different origins. Georelation as well as kinship is fundamental sources of social grouping. And migrants are more inclined to perform outdoor activity with people they trust, who are easily distinguished through accents. The sentiment which is considered to be geographically consolidated within fixed neighborhood and workplace is trans-localized with the mobility of people. And new community of conversant relationship is rebuilt in Sanya, which has a profound effect on social networking. As stated by one respondent, "North China Elderly's Association is great in uniting our laoxiang (migrants of identical origin) here in Sanya. We perform folkdancing, chorus and sometimes organize gathering with each other." She described how friendships develop through the association by bringing migrants together for events time and time again.
And respondents also feel a stronger sense of belonging with their laoxiang, "I feel comfortable and safety with snowbirds from northeast China. I think we are in a community, sharing common hobbies and lifestyle. I feel attached to the friends here". (Respondent 9) Being a snowbird is not an identity to get easy approval from all the subgroups, another kind of relation is common to be found between retirement migrants taking care of their grandchildren while holidaying in Sanya. They share a similar life routine, for example, to play outdoor with their grandchildren at 8-10 am and 4-6 pm everyday. It provides the occasion to form a baby-caring community, who are happy to share the living experience and caring about what happens to each other. However, contrary to Sixsmith's (1986) findings, a strong sense of community is not automatically arising from migrants' housing complexes or their "social home". Retirement migrants are more concerned about their families living in their primary residencies. It is common for migrants to be ignorant of or indifferent to their close neighbor. And they express no interest of knowing the neighbors in community. "I don't care about who is living next to me. Most of the owners rent out their houses, and the renters are very unstable. I never have a feeling of attachment to the community. I keep a phone talk with my friends and relatives in Urumqi... Long distance connection is important for me". (Respondent 9)

However, with the deepening of understanding and involvement in local society, some retirement migrants become active to participate in local affairs. While many retirement migrants are complaining about the incapacity, poor efficiency and even corruption of local government, some elderly move a step forward trying to remedy the social illness. They are experienced in community management, and feel obligated to take action. "With the settle-down of elderly snowbirds from north China, they began to be concerned with the community management issue. They participate actively in community service, public security management and share related working experience. It creates some positive effects in local." (Respondent 10, official from the Tourism Bureau of Sanya)

The social connection of laoxiang has seeded and facilitated sense of belonging and attachment for many seasonal retirement migrants in Sanya. The social aspect of home is tied closely with individual life circle, which is predominantly marked by social and cultural homogeneity of insiders. Long distance connection has transcended 
geographical vicinity of neighborhood to maintain sense of belonging for the migrants. And the majority of them mention that, they will eventually move back and stay in their place of origins when the really old age comes, because that's the real home they will ever cherish. On the other hand, retirement migrants are consistent in attitude towards local community. And a fortress city is being built under this discourse to further demolish the sense of social-insideness towards local society.

\subsection{Significance of Personal Identity and Interwoven Relation in Sense of Personal Home}

Personality influences how people adjust to life in their new communities, how they perceive them and how they behave in terms of creating a sense of home and belonging. It is meaningful to bring attention to the role of personal identity throughout the life circle (Peace et al., 2006 ${ }^{4}$ ). The personal aspect of home here concerns the person-centered process and the person-environment transaction in home building. Interviewees expressed a sense of recognition towards the intersect of time in place, experience of traveling and working in multiple places, which is influential in forming their sense of home in Sanya. As stated by one interviewee who had experienced commuting between Beijing, Shanghai and multiple cities internationally for work and had a long vacation in Hawaii after retirement, he found it an agreeable place to settle down. He reflected upon how many different locations he had dwell in and how they influence on his identity and expectation of retirement. The rich experience also gives him a fresh perspective on the person-environment relation and future development of Sanya.

In general, two types of personal identity of retired migrants are commonly identified. The majority of them describe themselves as adaptable, optimistic and generous; they are happy to be embraced by the ocean and the new life in Sanya. They are expecting to get involved in local life circle and value the connection found between laoxiang. And with the increase of dwelling time in Sanya, some elderly snowbirds develop a sense of valuing and contributing to local community, both through holding nighttime event to get local residents and seasonal migrants from different part of the country together, and by organizing

4. Peace, S.M., Holland, D. \& Kellaher, L. (2006) Environment and identity in later life. New York: Open University Press. community charity shows. Perhaps, such actions will encourage the development of personal skills that allow for roots to be laid down quickly, if somehow shallowly.

Yet, there is another type of retirement migrant who expresses viewpoint of tired of social engagement and sought a place of better calm and privacy. They consider getting involved in public activity is somehow annoying and troublesome. They prefer to stay in their own courtyard and spend time with the families. One of this kind of retirees are found in the higher-end gated communities, which are well-equipped and selfsufficed, and most of them are distinct from tourist spots and other residencies of seasonal migrants. The retired used to be successful in career and were occupied by socializing in work. Thus, they seek for a quiet place to enjoy the time with family. Another kind of people are found to be of physical incompetence. They are stepping in the later part of retirement, and are constrained by body disability. They find it difficult to participate in social life, and prefer to stay in the apartment or nursing house. For them, they expressed the viewpoint that they will stop holidaying in Sanya in the coming years and settle down in their own houses in hometown.

On a broader perspective, a graphic illustrating the reciprocal connections among different social parts can be drawn, encompassing behavioral and emotional relations between retirement migrant, local resident, government and managerial department and real estate developer ("Figure 2"). Through residing in Sanya, seasonal retirement migrants are repositioning their roles in local community, while constructing sense of home and rootedness. The majority of migrants have undergone a transition in perception of home with growing control over self and surrounding environment. For example, with the establishment of specialized dwelling space and increased population of seasonal retirement migrants, they are getting more self-affirmative and intra-group cohesive. Some neighborhoods become famous for the concentration of retirement migrant from one place, such as the "Peking village", the "Northeast China village" and "Henan village". The neighborhoods are effective in facilitating the emotional connection between laoxiang and fostering a sense of belong with familiar living circumstances. A cognitive home space is recreated by homogeneity of residents in language, dwelling preference, food and lifestyle. "Living in the socalled 'Northeast China village' gives me a feeling of safety and belonging. People are united here. It 
just feels like I'm living in Harbin again. (Respondent 15)" Furthermore, by involving into the "acquaintance society" formed primarily by laoxiang, retirement migrants retrieve a sense of attachment and further confirm the possibility of emotional home in a second residency. However, local society and indigenous residents are void in this new home, and there is a large space that deters the involvement of local government. "Sanya seems no longer a city of Hainan Province now, rather, it is a part of north China. There were approximately 0.4 million snowbirds spending the winter and Spring holiday in 2013. The seaside is crowded with snowbirds with different accents. The locals are stepping back, to their fishing villages or farmland in the interior and peripheral areas of the city". (Respondent 16)



Figure 2 Behavioral and emotional relations between multiple social parts.

Self-identification is an important factor influencing how people fix in the new environment, how they perceive the social connection and how they behave. Different behavioral, cognitive and emotional aspect of home is thus visualized through divergent personality of the retirement migrants. Additionally, through the construction of home, seasonal retirement migrants are effecting manipulation on environment, by employing the power of collective actions. The sense of control and belonging of the migrants has a lot to do with the "acquaintance society" formed by familiar social connections. The social network is transplanted from the "primary home" and revitalized in a new home space, by which migrants manage to maintain a sense of rootedness in constant mobilization.

\section{CONCLUSION}

This research is conducted based on interviews with retirement migrants aged $60 \mathrm{~s}$ to $70 \mathrm{~s}$ from north China to Sanya, Hainan Island. The entire sample of the interviewees consists of seasonal retirement migrants who have spent winter holiday in Sanya for less than 7 years, which is a comparatively short time for the establishment of deep roots. Yet, many interviewees have expressed a view towards the physical beauty and agreeable climate of Sanya as a desirable place for a second residency, and show some extent of attachment to their neighborhoods of acquaintance. Seasonal retirement migrant's perception of home is a result of the reciprocal interaction between person and environment. And as stated by Fisher and Harvey (2009), through ongoing negotiation and transaction between people and their environment, the "being in place" is constantly evolving across time and space.

The connotation of home develops with increased experience by the retirement migrants. For the older people, quality, comfort as well as safety of physical environment are important. Gated community is introduced in the second home compound, to establish residential homogeneity and block the local strangers outside. It is important for the migrants to establish a feeling of safety and certainty in new environment, so long as to avoid the awkward and uncomfortable time with the locals. Social connections are also bonded to retain a sense of home both within and outside of the second home communities. Through the long distance away from home, traditional "laoxiang" become extended social network for the snowbirds who are eager to grab a sense of familarity in time of change. "Laoxiang" are no longer ordinary passerby in their cities, but are endowed with profound social significance for identity. The acquaintance society formed primarily by "laoxiang" is important for the olds to identify 
subcultural groups with similar lifestyle and social status. The symbolic meaning of second home is highlighted in this context. Whereas home traditionally represents root and connection with the place, it is meaningful as a symbol of social status or elite in the second home space.

The difference between retirement second home and original home is marked by the social distinction of residence. For the olds in China, the home space is typically "set up" to be comfortable, located close to reliable social relations and is bounded with precious memory and family affection in the whole life. Such places become "control centers" or "living centers" within the residence and probably serve adaptive functions such as maintaining and enhancing control and comfort over the immediate environment (Lawton, 1985; Oswarld, 1996; Rubstein \& Parmelee, 1992). With increase tempo-spatial fluidity, people are more earnest in search of subgroups of similar lifestyle and social status. By griping hold of laoxiang's community, migrants get control in their life and maintain the status quo. And it turns out to become a useful way for one to cope with change and reconstruct a sense of home when living elsewhere. Traditional communities formed by households of similar occupation in the first place are diversified by the social composition of residents. The ability to move into another space marks the difference in resident's understanding of home and "home away home".

This research views the heuristic framework of Oswald and Wahl (2005) as a valuable tool for building understanding about the meaning of home for older adults by drawing attention to the three domains. The entwined nature of the domains also leads us to reflect on the dynamic interaction of person and the complex social background. Generally speaking, the meaning of home plays an important role as an element in the process of relocation to another place of residence; it reflects the outcome of coping processes in the face of environmental changes. Relocation in old age covers moving from home to home, from home into caring facility. The meaning assigned to a home influences the decision to move and moving into a new home initiates a process of reestablishing meaning in the new place through living there (Rowles \& Ravdal, 2001). The case study of Sanya provides a new understanding on home perception in mobilization, which is in contrast with the traditional belief in China that home is a spatially fixed and emotionally static concept. It sheds light on the loss in consumption and unhomeliness with increased mobility in current urban, and the coping strategies to obtain rehabilitation and restoration.

\section{AUTHORS' CONTRIBUTIONS}

This paper is independently completed by Yuefang $\mathrm{Wu}$.

\section{REFERENCES}

[1] Aledo, A. (2008) De la tierra al suelo: la transformaci ó $\mathrm{n}$ del paisaje y el Nuevo Turismo Residencial. ARBOR Ciencia, Pensamiento y Cultura, 729, pp.99-113.

[2] Blunt A (2005a) Cultural geography: cultural geographies of home Progress in Human Geography 29, 505-15

[3] Blunt A (2005b) Domicile and diaspora: Anglo-Indian women and the spatial politics of home Blackwell, Malden MA.

[4] Blunt, A., \& Varley, A. (2004) Geographies of home Cultural Geographies, pp.113-116.

[5] Castels, S. And Miller, M.J. (1993) The Age of Migration. International Population Movements in the Modern World, LondonL Macmillan Press Ltd.

[6] Chan, C. (1993) The Myth of Neighbourhood Mutual Help. Hong Kong: Hong Kong University Press, pp. 215.

[7] Chan, W.Y. (2003) Home but not home: a case study of some canadian returnees in Hong Kong. A thesis presented to the Hong Kong University of Science and Technology, pp. 106.

[8] Clifford, J. (1997). Routes. Cambridge: Harvard University Press.

[9] Cutchin, M. P. (2001) Deweyan integration: moving beyond place attachment in elderly migration theory. International Journal of Aging \& Human Development, 52(1), pp.2944.

[10] Denise, C.H., \& Harvey, J. (2009) Home beyond the house: Experiences of place in an evolving retirement community. Journal of Environmental Psychology, 29, pp.246-255

[11] Dovey, K. (1985). Home and homelessness. In I. Altman, \& C. M.Werner (Eds.), Home environments: Human behavior and 
environment, Vol. 8 (pp. 33-54). New York: Plenum Press.

[12] Fei, X.T. (1945) Earthbound China.

[13] Giddens, A. (1984) The Constitution of Society: Outline of the Theory of Structuration, Cambridge: Polity Press.

[14] Gloant, S.M. (2003) Conceptualizing time and behavior in environmental gerontology: a pair of old issues deserving new thought. The Gerontologist, 43(5), pp.638-648.

[15] Gustafson, P. (2001) Retirement Migration and Transnational Lifestyles. Ageing and Society 21:371-394.

[16] Hayward, D. G. (1975) Home as an environmental and psychological concept. Landscape, 20, 2-9.

[17] Ikels, C. (1996) The Return of the God of Wealth: The Transition to a Market Economy in Urban China. Stanford, CA: Stanford University Press.

[18] Jankowiak, W.R. (1993) Sex, Death, and Hierarchy in a Chinese City. New York: Columbia University.

[19] King, R., Warnes, A.M., Warnes, T., \& Williams, A.M. (2000) Sunset lives: British retirement migration to the Mediterranean, New York: Berg.

[20] Peace, S.M., Holland, D. \& Kellaher, L. (2006) Environment and identity in later life. New York: Open University Press.

[21] Rapport, A. (1988) Levels of meaning in the built environment. In F. Poyatos (Ed.), Crosscultural perspectives in nonverbal communication (pp. 317-336). Toronto: Hogrefe.

[22] Rowles, G.D. (1983) Geographical dimensions of social support in rural Appalachia. In G.D. Rowles \& R.J. Ohta (Eds.), Aging and milieu: Environmental perspectives on growing old (pp. 111-130). New York: Academic Press.

[23] Valentine G, Sporton D and Nielsen K B 2009 Identities and belonging: a study of Somali refugee and asylum seekers living in the UK and Denmark Environment and Planning D: Society and Space, 27, pp.234-50.
[24] Walsh, K. (2011) Migrant masculinities and domestic space: British home-making practices in Dubai Transactions of the Institute of British Geographer NS, 36, pp. 516-29.

[25] Wiles, J. (2005) Conceptualizing place in the care of older people: the contributions of geographical gerontology. Journal of Clinical Nursing, 14(8B), pp. 100-108.

[26] Zingmark, K., Norberg, A., \& Sandman, P.O. (1995) The experience of being home throughout the life span. International Journal of Aging and Human Development, 41, pp. 47-62. 